\title{
SERÁ O SÉCULO XXI UM SÉCULO CHINÊS?
}

WILL BE THE XXI CENTURY A CHINESE CENTURY?

\author{
Pedro Geiger \\ Universidade do Estado do Rio de Janeiro (UERJ), Rio de Janeiro, RJ, Brasil, pedro.geiger@gmail.com
}

\section{RESUMO}

Uma rápida ascensão econômica e política chinesa suscita diversas questões, como a respeito de futuras hegemonias e transições do modo de produção. Depois de descrever as dimensões e as qualificações do crescimento chinês, comuns em certo grau ao que ocorre com outros países de tamanho continental, como os do BRIC, e que se dá no contexto da globalização, o trabalho trata de teorias relativas a este desenvolvimento. São abordados temas como o deslocamento histórico espacial da hegemonia através da colagem cultural de uma nova hegemonia num país hegemônico precedente; as mudanças de modo de produção; o papel do Estado e de soft power no processo histórico; as condições geográficas para o desenvolvimento. A conclusão é que no tempo de globalização multipolar não se repete a hegemonia de um ou dois países, e que a verdadeira pergunta diz respeito ao papel do Estado e a quando e onde se dará uma completa transição do capitalismo.

Palavras-chave: China; globalização; BRIC; modo de produção; multipolaridade.

\begin{abstract}
An accelerated economic and political Chinese ascension provokes diverse questions as in relation of future hegemonies, or future mode of production transitions. After describing the dimensions and the qualifications of Chinese growth, which is common in a given degree with other countries of a continental size, as the BRIC, and that happens in the globalization context, the paper deals with theories related to such development. One deals with issues as the historical movement of hegemony from countries from East to West, where a hegemonic country learned from a neighbor precedent power; as the role of the State and of the soft power in building hegemony; as the geographical conditions for development. One concludes that in times of multi polar globalization, the true question is about future State roles and about when and where a complete transition from capitalism will occur.
\end{abstract}

Keywords: China; globalization; BRIC; mode of production; multipolarity

Artigo recebido para publicação em outubro de 2015

Artigo aceito para publicação em dezembro de 2015

\section{INTRODUÇÃO}

Entre as atuais especulações futuristas, destaca-se a que trata de uma possível dimensão política mundial a ser ocupada pela China no século XXI. Será que este século será chamado no futuro como tendo sido o "século chinês", conforme anunciado por Arnold Toynbee?

A pergunta se fundamenta no rápido desenvolvimento que vem sendo apresentado pela China e no seu peso territorial e populacional. A questão é tanto maior, uma vez que ela não se restringe à distribuição geográfica do poder, ao formato do mapa geopolítico segundo os seus Estados/Nações. A China sucede à extinta União Soviética, como um poderoso país dirigido por um partido comunista, de modo que a 
pergunta compreende a interrogação quanto ao formato da economia política que passaria a ser dominante no mundo.

A pergunta se apresenta quando se assiste a um agravamento da crise política e ideológica que afeta 0 modelo histórico da democracia capitalista. Ela é acompanhada pela multiplicação de movimentos antisistêmicos. No centro capitalista e no seu entorno mais desenvolvido manifestam-se descréditos à clássica forma da representação política pluripartidária, enquanto crescem as manifestações populares de rua convocadas espontaneamente pela própria população, observado, por exemplo, no Brasil nos anos recentes. Movimentos que se apresentam em contradição ao aumento do centralismo estatal, na Rússia, no Brasil, e mesmo nos Estados Unidos. Na Europa se observa inclusive o recrudescimento de movimentos fascistas e um reforço de movimentos separatistas, como ocorre na Escócia. Em regiões periféricas ao centro histórico do capitalismo, menos desenvolvidas, como na América do Sul, novas formas populistas e nacionalistas conquistaram o poder estatal, como no caso do regime bolivariano venezuelano, e reações também ocorrem contra os mesmos. Em regiões islâmicas verifica-se o crescimento da intervenção de fundamentalismos religiosos na política, a constituição de regimes clericais e tanto revoltas contra os regimes relativamente laicos, como guerras entre facções fundamentalistas e descontentamentos nos regimes clericais. Um verdadeiro caos. Uma sensação de desordem geral está sendo estabelecida.

Enquanto isso, os sinais emitidos pela China compreendem a velocidade do seu desenvolvimento econômico, a sua influência política e diplomática na arena internacional; o elevado grau dos seus investimentos internos e externos, e o seu papel financeiro em outros países. Acresce-se a elevação de seu poderio militar e a modernização de sua estrutura social em meio à rápida urbanização.

É verdade que o regime chinês também apresenta manifestações sociais de descontentamento contra 0 tolhimento de maiores liberdades individuais, presentes nas democracias capitalistas. No entanto, o atendimento a estas demandas, sem colocar em risco os princípios que norteiam o regime, parece ser mais plausível no caso chinês do que no centro capitalista, nas periferias sul americanas, ou no mundo muçulmano. 
A camisa de força religiosa torna mais difícil a abertura democrática em países muçulmanos. De um lado, a difusão religiosa pela população com que esta população dê suporte ao fechamento, e de outro lado, a abertura aparece como ameaça a uma aliança de classe e estamentos estabelecida no poder: a classe de proprietários e estamentos clericais e de setores militares. Já na América do Sul, nos países populistas autoritários, a maior liberdade vem sendo identificada com um retorno à liberdade da classe dominante manter a sua alta exploração. 0 regime de fechamento é sustentado pelas massas populares de baixo nível econômico e de conhecimento, a maioria populacional, enquanto a oposição reúne as camadas mais altas e setores populares mais educados. No centro capitalista, as demandas esbarram num sistema há muito estabelecido e que contém a desigualdade como inata. Já o regime chinês pode oferecer, paulatinamente, concessões a uma expansão popular de demandas, sem colocar em risco 0 regime, mantendo uma legitimidade fundada no crescimento econômico constante. O que a antiga União Soviética não conseguiu.

Assim, enquanto se assiste ao crescimento interno e externo da China, surgem sinais paralelos de tendências de mudanças na ordem social mundial. Eles estão sendo emitidos de diversas partes do mundo e expressam o descontentamento de massas de população com o status quo presente.

O presente trabalho se restringe a tratar da recente ascensão da China e de seus significados. 0 exame das manifestações da crise geral contemporânea, que se segue à crise econômica financeira que atingiu o auge no período de 2009 a 2012, e o papel da China nesta crise ficam para outra ocasião.

\section{A ascensão chinesa}

A ascensão da China resulta de uma convergência de interesses. De um lado, a revolução comunista chinesa, com o seu ideário de mudança social e superação de interesses particulares, que conduziria ao crescimento econômico. Do outro lado o movimento horizontal do capitalismo, representado principalmente pelo setor americano, em seu afã de conquistar novos mercados e que culminou com a 
globalização, na qual a China passou a ter um papel principal. O capitalismo é como a bicicleta que 0 ciclista necessita rodar para que ela se mantenha em pé.

País mais populoso do mundo, de dimensões continentais. Cerca de 8 milhões de quilômetros quadrados, a China vinha sendo dilacerada e humilhada durante a modernidade até a Segunda Grande Guerra, primeiro pelas potências imperialistas europeias e depois pelo Japão. A reação política chinesa às debilidades estruturais do país se deu na forma de dois movimentos sociais, um de cunho nacionalista, que passou a ocupar a direção formal do Estado, e um outro comunista, que formou um exército popular. Os dois movimentos entraram em luta armada contra o Japão e entre si. O suporte dado pelos Estados Unidos ao governo nacionalista de Chiang Kai Chek na luta contra o Japão foi a principal motivação do ataque a Pearl Harbor, em 7 de dezembro de 1941. A relação entre os Estados Unidos e a China se solidificou. Deve se levar em conta a manutenção dos valores tradicionais chineses para a compreensão mesmo das relações atuais entre os dois países.

Vitoriosos na Guerra, ao lado da antiga União Soviética e do Reino Unido, a China ganhou um assento no Conselho de Segurança das Nações Unidas de 5 países com direito de veto - os acima citados e a França. Esta posição política, que oferece papel maior nas decisões mundiais, contribui para o destaque que a China possui entre os chamados emergentes.

Apenas quatro anos se passaram para que os comunistas chineses liderados por Mao Zedong derrotassem os nacionalistas, que se refugiaram em Formosa e assumissem o governo da China continental, em 1949. No começo da revolução comunista chinesa, sob o comando de Mao Zedong, a cooperação econômica atual entre a China e os Estados Unidos seria inacreditável, o Partido Comunista Chinês, PCC, seguia a linha Leninista, aprofundada pelo stalinismo, de ruptura total com o capitalismo. Repetiam-se os erros napoleônicos de imaginar que as transições do modo de produção se realizam pela força, ignorava-se ainda com maior profundidade o conceito de formação econômica social (MARX e ENGELS, 1996, LUPORINI e SERENI, 1974). 
Durante um tempo os dois países se ignoraram, sem o reconhecimento da China Comunista pelos Estados Unidos. Até que a genialidade de Kissinger, ao lado do presidente Nixon, selou o retorno às relações. A mudança na liderança comunista chinesa, que passou para o grupo de Deng Xiaoping, introduziu nova orientação ideológica e estratégica, acompanhada de reformas legais, que conduziria ao estreitamento das relações econômicas entre os dois países.

É interessante recordar que na história da antiga URSS, há um capítulo parecido com o escrito por Deng, mas, que terminou no fracasso de uma tentativa de reforma do regime soviético. Trata-se da tentativa do grupo de Bukharin, nos anos 1930, e que acabou com o fuzilamento de Bukharin e de diversos membros do seu grupo.

Para manter o capitalismo em movimento, o centro capitalista formado pelos Estados Unidos, USA, União Européia, EU, e Japão, ofereceria capital e tecnologia. A China compareceria com mão-de-obra abundante, aplicada e disciplinada, e barata. Na sua política de modernização, a China instituiu controle severo de natalidade, outra reviravolta em relação à antiga estratégia de Mao, a da "bomba demográfica", tendo preferido absorver tecnologia do centro capitalista e construir a "verdadeira" bomba A. No entanto, a urbanização chinesa sustentaria grande reserva de mão-de-obra e salários em ascensão moderada.

Assim, o movimento horizontal do capitalismo se articularia com o seu movimento vertical, inundando o mundo com produtos industriais com preços relativos aceleradamente decrescentes. Em suas primeiras fases da ascensão chinesa, anos 1980 e 1990, o país aparece principalmente como uma plataforma de exportação. No entanto, neste ínterim foi criando uma classe de empresários e executivos nacionais, paralela aos executivos das empresas estatais, e ampliando o consumo interno. No presente, o mercado interno se torna crescentemente uma base do crescimento econômico chinês e um instrumento dos gigantescos passos sociais tecnológicos e culturais. Sem tradições religiosas, sem os votos de pobreza, principalmente da tradição católica, Deng proclamou a beleza da riqueza. 
A situação que se está criando com esta ascensão aparenta levar à criação de uma situação mundial que lembraria o quadro de bipolarização que se instalou durante a "guerra fria" do após Segunda Grande Guerra, embora numa forma muito menos marcante. Como se sabe, a história não se repete. Quando a Segunda Guerra terminou, o panorama mundial mostrou a presença de apenas duas potências de dimensão continental, cada uma, e que se tornaram monopolistas da arma atômica. Agora são diversos os países de dimensão continental em emergência e o armamento atômico é possuído por nove países.

O novo mapa mundial, o da globalização, mostra uma primeira linha composta de países de escala continental, isto é, caracterizados por área imensa e populações de cem milhões de habitantes para mais.

Os EUA foram os primeiros a inaugurarem um quadro de Estado/Nação como uma economia industrial altamente desenvolvida de escala continental. O processo desta instalação compreendeu a transferência contínua de massas de população da Europa para os Estados Unidos, e de chineses, japoneses e sul americanos. Ampliando a sua presença no cenário mundial no século XX, principalmente após a Segunda Grande Guerra, a continentalidade americana foi um forte diferenciador do país em relação aos demais países do centro histórico capitalista, as potências da Europa ocidental e central e o Japão.

Após a Primeira Guerra Mundial de 1914-18, a instalação da União das Repúblicas Socialistas Soviéticas projeta um outro modelo de Estado de dimensão continental, que durante parte da segunda metade do século XX chegou a formar uma bipolaridade do poder mundial com os Estados Unidos. Neste período começam a se destacar no mundo outros Estados gigantescos, como a Índia, o Brasil, e a China em particular, pela economia e presença política. A Alemanha nazista também tentara reproduzir o modelo continental pela força, anexando países e com o seu projeto de Europa, que seria por ela comandado. A ideia de uma Europa unida se concretizaria somente após a Segunda Grande Guerra, sem hegemonia política de um único membro, com a constituição paulatina da União Europeia. 
A formação de países de grandes dimensões se apresentou historicamente por razões de integração étnica, caso da Rússia, ou de políticas coloniais, caso do Brasil. Quando a industrialização iniciou a se instalar no mundo, estes grandes países tiveram maior dificuldade de participar, seja por razões culturais, seja por razões de alometria e da dispersão de sua população. Do mesmo modo pelo qual os dinossauros se tornaram presa fácil dos tiranosauros, a alometria contribuiu para que países de grande dimensão fossem dominados por países infinitamente menores. Exemplos marcantes foram o longo domínio do Congo pela Bélgica, ou da Indonésia pela Holanda.

Os Estados Unidos, porém, herdaram a cultura da modernização e da industrialização inglesa, construíram um sistema ferroviário, descobriram e inventaram a utilização do petróleo, e instalaram rede rodoviária ainda mais densa, para superar efeitos alométricos e ganhar agilidade. No Brasil, durante muito tempo, a ferrovia servia principalmente ao papel de conduzir mercadorias de exportação agrícola das regiões de produção para o porto. Países como o Brasil e China ganharam força ante as debilidades do gigantismo ao iniciarem a sua industrialização para se tornarem as atuais "baleias" (mais ágeis que os elefantes, por razões alométricas) na designação de Pinheiro Guimarães (GUIMARÃES, 2005).

Portanto, foi necessário que países como o Brasil, a Índia e a China atingissem um determinado nível de desenvolvimento para que o fenômeno da globalização assumisse corpo, e no qual a China exerce papel maior de componente.

A ascensão chinesa aparece assim como parte de um processo mundial que, entre outros aspectos, mostra o fortalecimento de Estados de grandes dimensões territoriais e sua elevação como potências mundiais. Seria uma solução encontrada pelo capitalismo que, tendo surgido numa Europa muito dividida nacionalmente, teve que enfrentar uma sucessão de guerras destrutivas.

No entanto, o distanciamento dos Estados Unidos e da China das outras economias mundiais e dos demais países em geral, é enorme em termos do PIB. Os Estados Unidos comparecem com mais de 18 trilhões de dólares, a China com cerca de 12 trilhões, enquanto o Japão, o terceiro, fica em torno de 8 
trilhões. Porém, a China vem mantendo um crescimento anual em torno de 7\%, os Estado Unidos, em torno de $3 \%$, enquanto o Japão cresce a $1 \%$ e a quarta economia, a alemã, abaixo de $2 \%$.

A relação recente entre os dois países líderes, USA e China, apresentou um fato particular que ampliou a dependência entre ambos. A China passou a aplicar os seus altos saldos decorrentes da balança de contas positiva na compra de papéis de divida americana.

\section{Questões teóricas associadas à ascensão chinesa}

1. A marcha da civilização para o oeste. $\mathrm{O}$ oeste é a linha de fuga valorizada pela cultura americana. 0 eminente scholar americano, David Wilkinson, da UCLA e da International Society for Comparative Studies of Civilizations, ISCSC, observou o deslocamento da civilização e dos impérios do Oriente Médio para a Grécia, depois para Roma, para a Inglaterra e para os Estados Unidos. Este movimento circular, que atingira o Japão, sob influência americana, estaria chegando à China, também por influência americana?

Acrescenta-se a esta proposição um mecanismo explicativo. Regiões situadas a oeste do então mundo de elevado desenvolvimento civilizatório tratavam de se colar ao mesmo e absorver conhecimentos deste mundo, até assumirem a liderança. Foi o que fez a Grécia em relação ao Egito e ao Oriente Médio; Roma, em relação à Grécia; a Inglaterra, em relação ao Renascimento italiano e à Grécia; os Estados Unidos em relação à Inglaterra. Assim como Newton sucedeu a Galileu, assim, a escola marxista americana segue a escola inglesa.

Não é que a China milenar necessite de influência para ser um centro civilizatório, mas, a sua tradicional civilização não seria suficiente para colocar um homem no espaço. Hoje, é a única além dos Estados Unidos e da República Federativa da Rússia capaz de fazê-lo. A política chinesa atual compreende o envio de dezenas de milhares de estudantes anualmente para freqüentarem as universidades americanas, a difusão da língua inglesa, a cooperação entre as instituições científicas e culturais dos dois países. 
2. Um aspecto particular da ligação sino-americana. Um aspecto particular da relação entre a China e os USA deixou ambos dependentes, um do outro. O governo chinês passou a utilizar o seu elevado saldo do balanço de contas para adquirir papéis do Tesouro americano. Nesta transação, hoje na casa do trilhão, a China se assegura de uma reserva forte e que lhe rende juros. Quanto aos americanos, este investimento significa o retorno de dólares ao país, gastos na importação, e que assegura, sem maiores danos, o permanente déficit da balança comercial. A China sustenta a dívida americana. Neste jogo interessa à China que o dólar siga valorizado, o que mantém o valor de suas reservas e a competitividade nas suas exportações através de sua moeda, iene, mais fraca. Aos Estados Unidos interessa que a China continue financiando a sua elevadíssima dívida interna.

Nesta relação, a China dispõe da ameaça de retirar as reservas e transferi-las pra outra moeda, ou moedas; porém, os Estados Unidos podem revidar cortando as importações chinesas. Encontram-se presos um ao outro.

Críticas de esquerda surgiram em relação à esta prática financeira realizada pela China, argumentando que o dinheiro poderia ter sido utilizado para elevar o padrão social do trabalhador chinês, cuja evolução é lenta. A inclusão de formas trabalhistas ocidentais, como férias anuais de 30 dias e outras, é muito recente. Na China, antigas práticas tradicionais incluíam festejos de semanas de duração, à semelhança do que ocorre com os feriados religiosos judaicos, com interrupção de trabalho. Foi necessário o governo chinês reduzir a influência destes festejos no trabalho para criar novo calendário para o mesmo.

O contra-argumento em defesa da política de criar reservas é de que a aplicação dos saldos para fins sociais excessivos levaria à inflação. Seria melhor fortificar o Estado, desenvolver o crescimento econômico para melhor alavancar as medidas sociais. Um dilema que levou o Brasil à situação atual. 0 que conduz ao ponto seguinte desta seção, o da transição do modo de produção. 
3. As transições do modo de produção. Em Imperialismo, Etapa Superior do Capitalismo (LENIN, 1979), as Guerras Mundiais são consideradas inerentes ao capitalismo e as revoluções armadas seriam os caminhos da mudança dos modos de produção. A destruição operada pela guerra, em termos de força-de-trabalho e de meios de produção, serviria ao equilíbrio de oferta e demanda afetado pela inevitável superprodução capitalista. Seria um aspecto inevitável de “destruição criativa" (SCHUMPATER, 1961).

No entanto, nem feudalismo, ou mercantilismo, ou capitalismo se propagaram por meio da força, mas, através de relações comerciais e culturais entre povos. A ideia de um corte radical entre os sucessivos modos de produção negaria, de alguma maneira, o conceito da formação econômica social que considera o engavetamento de uns nos outros A negação da tese leninista e a não participação na revolução espartaquista alemã, que previu fracassada, influiu na expulsão de Kautsky do Partido Comunista. Kautsky lera o livro The Great Illusion do economista Angell Norman, (NORMAN, 1910), no qual o autor previa acordos entre os capitalistas para abortar as guerras que estavam se tornando muito custosas.

Considerando as intervenções militares externas para debelar a "Revolução de Outubro", e que se estenderam aos primeiros anos 20 do século 20, entende-se a visão leninista. Porém, para observadores sagazes, ações dos anos 1940-50, como as de Chamberlain tentando evitar a Segunda Grande Guerra a todo custo, ou as dos Estados Unidos só entrando na mesma depois de atacados, mostrariam que Norman estava com razão. No entanto, a tese leninista serviria para Stalin transformá-la na linha nacionalista que lhe asseguraria poder pessoal, fazendo-o rejeitar a oferta do Plano Marshall e proibindo os países satélites de aceitá-la.

A China mantém a efígie de Lenin ao lado da de Marx em suas bandeiras ideológicas, mas, abandonou a linha radical comunista nas suas políticas internas e externas. Sustentando o crescimento de importante setor empresarial privado, ao lado das empresas estatais; dando suporte a um sistema de Estados atuantes na sustentação da globalização; estendendo as suas relações comerciais e financeiras por todas as partes do mundo; se abstendo de uma pública anunciada competição tecnológica e militar 
com os Estados Unidos, a cabeça do capitalismo; evitando cair em colonialismos políticos clientelistas e criação de países satélites e se abstendo de campanhas ideológicas, quer de críticas ao capitalismo internacional, quer de loas ao socialismo. Limita-se em apresentar as realizações de seu regime e tecer perspectivas para a construção do que chama socialismo de mercado.

O marxista italiano Domenico Losurdo distingue, na atualidade, um marxismo ocidental e um marxismo oriental. O primeiro, na continuidade do movimento iniciado no centro histórico do capitalismo se ocuparia com a evolução da questão da classe. 0 segundo, como que mantendo a visão maoísta, de que na contemporaneidade a contradição se encontra na desigualdade de nações, se desenvolve entre os países emergentes, sustentando o seu empenho em assumir o topo mundial, com novas formas na relação de classes. Que novas formas?

Nicos Poulantzas (POULANTZAS, 1976) enfatizou o político na expressão Economia Política, uma vez que o poder político é o almejado através da base econômica. A classe burguesa capitalista aceita ceder concessões e mais concessões econômicas financeiras à classe trabalhadora, mas não pode permitir o regime político do partido único de trabalhadores. A diferença da China das outras potências seria o seu regime do PCC como partido único.

Mas, o que é hoje um partido de trabalhadores? De um lado, a expansão dos serviços qualificados e da automação reduz, em termos relativos e absolutos, o número do proletariado, a raiz originária da concepção de luta de classe. A automação também reduz o clássico setor camponês da luta de classe. De outro lado, se expande aceleradamente o setor dos executivos, nas atividades privadas e públicas, espécie de híbrido de capitalista e trabalhador, via de regra, como formados universitários. Tecnicamente, os executivos vivem de salários, de bônus, e administram o capital. Quem dirige a China são os executivos do Estado e do Partido.

Deste modo, abre-se a questão do capital. István Meszáros afirma que o problema do capitalismo não são os capitalistas, mas a natureza do capital, a extração de mais valia. (MESZÁROS, 2011). Significa isto que um regime comunista elimina o capital? 
Termos e conceitos se formaram historicamente e a relação entre um termo e um conceito pode se alterar ao longo do tempo. É comum se acrescentar um adjetivo para ilustrar as mudanças históricas que afetam um determinado termo. Por exemplo, mercado é um termo criado num passado profundo, antes do advento do capitalismo, quando produtores de produtos agrícolas, comerciantes e consumidores se encontravam num determinado local, fixo, para realizarem transações entre si. 0 termo atravessou os tempos e na atualidade se acrescenta um adjetivo, como, mercado de capitais, mercado de commodities, que revelam novas naturezas para o termo mercado. Do mesmo modo, é provável uma permanência duradoura para o termo capital, atravessando diferentes modos de produção, tendo em comum a sua diferenciação de dinheiro. Dinheiro, moeda de consumo, capital, moeda de investimento.

A ascensão chinesa, articulada com a globalização, decorre e ativa o crescimento do fluxo de capitais que caracteriza esta globalização e que fez da China um foco central. Portanto, assiste-se a uma articulação histórica, a do capital, com o movimento comunista. Uma declaração da liderança chinesa marxista, de que o país está instalando uma economia de "socialismo de mercado" expressa certamente a sua percepção da referida articulação como um passo de transição no modo de produção.

Quanto à questão do espaço de representação política pluripartidária (LEFÈBVRE, 1974), note-se a crise por que passa, mesmo nos países de democracia capitalista, com a multiplicação das ONGs e dos movimentos de rua. No mundo da velocidade compatível com os avanços tecnológicos, as formas democráticas tradicionais de gestão e de suas formas de tomada de decisões aparecem freqüentemente como extremamente ineficazes. Nos Estados Unidos, por exemplo, em 1915, estourou o prazo para o Congresso aprovar o Orçamento, fechando o acesso do público a serviços federais. Uma vantagem da China em relação aos Estados Unidos é justamente a maior agilidade nas decisões devida ao partido único de governo.

4. A geografia. Os Estados Unidos apresentam, em contrapartida, condições geográficas mais favoráveis. Como possuir maiores riquezas geológicas e também melhores condições pedológicas. 
Apesar dos balísticos, sem vizinhos poderosos, e isolada de outros continentes pelos dois maiores oceanos que lhe oferecem o comércio marítimo através de duas enormes costas abertas, a América do Norte leva vantagens de segurança em relação à China. Os Estados Unidos não apresentam problemas políticos observados na China, como os movimentos separatistas do Tibet, dialetos diferentes entre suas regiões, oposições maometanas em suas províncias ocidentais.

Note-se que, na atualidade, a tonelagem transportada no Pacífico já supera por pouco a do Atlântico. No Atlântico, a maior carga vem do Leste para os Estados Unidos, do que para a Europa. No Pacífico, a maior carga vai para o Leste, da China, Japão, Coreia, para os Estados Unidos. Contudo, os Estados Unidos participam do movimento dos dois oceanos e de associações políticas de países das orlas dos dois oceanos. Na América do Sul, países como a Colômbia, Peru e Chile, membros, como os Estados Unidos, de bloco comercial do Pacífico, apresentam, atualmente, os maiores índices de crescimento econômico do continente.

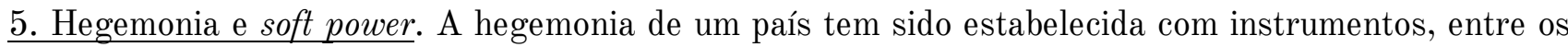
quais a difusão de produção cultural original, entre as quais, a sua própria linguagem. A ascensão da hegemonia americana após a Segunda Guerra consolidou o inglês como a língua franca contemporânea e esmagou o francês que era utilizado na diplomacia internacional. Um outro exemplo clássico de soft power, poder suave, americano, diferente do hard power, poder duro, das armas, é o do cinema que inundou o mundo com a ideologia americana de comportamento humano.

É difícil imaginar a língua chinesa substituindo o inglês como idioma internacional. Aliás, a rigor, a língua inglesa possui já autonomia própria independente de um país, é idioma oficial de vários países. Note-se que o Latim permaneceu como língua franca durante séculos depois do fim do Império Romano.

A China começa a dar os primeiros passos no sentido de produzir um soft power próprio. A expressão, criada por Joseph S. Nye Junior, de Harvard, com referência a intercâmbios comerciais e culturais, foi pronunciada no Congresso do PCC de 2007 e repetida em 2013 pelo então Presidente da China, Xi 
Jimping, ao mencionar a necessidade do país aperfeiçoar a sua capacidade de comunicação internacional.

Acompanhando o Encontro da Academia da Latinidade, presidida por Cândido Mendes, em Kuala Lampur, em 2013, Merval Pereira observou a aproximação chinesa ao tema do soft power (PEREIRA, 2014), tendo o professor de filosofia chinês Tong Shizun, da East China Normal University tratado explicitamente do tema. Foi lembrado que um radical pensador do PCC, Lu Xun, defendeu a necessidade do país se integrar com o Ocidente e que declarara que "raça que acresce os outros sem refletir sobre si mesma é fadada a perigos e desastre. A raça que tem muitos que não são complacentes consigo mesmo vai sempre andar para frente".

Para o mencionado Tong Shizun, um soft power chinês teria um conteúdo cultural e político que se originaria da longa tradição civilizatória chinesa de compartilhar aprendizado e paz. Somaria à mesma o grande ideal revolucionário de "grande contribuição à humanidade" e de realização do socialismo com características chinesas. Socialismo de mercado, com democracia e Estado de direito, com cultura nacional cosmopolita e ecologicamente correto.

A China parte com um projeto de Estado com princípios estabelecidos, assim como a "revolução americana" tinha estabelecido os seus, como o do Estado mínimo, de liberdade de opinião e expressão e da igualdade de todos perante a lei.

A China se valeu da experiência dos fracassos soviéticos e da sofisticação crescente na evolução do pensamento marxista inserida no progresso geral da ciência social contemporânea. É claro que o desenvolvimento de um soft power chinês se encontra numa fase muito inicial, quando o país, como é comum após guerras civis, ainda vive situações de autoritarismo, censura e corrupção.

A questão da falta de plena democracia tem sido levantada como obstáculo para a aceitação do modelo chinês. No entanto, o modelo capitalista apresentou características que tão pouco são aceitas nos dias atuais, como o voto negado às mulheres, a discriminação racial, e outras. 
Um aspecto inovador chinês é o crescente culto à meritocracia, a ser aplicada inclusive paralela ao voto popular na formação dos corpos representativos, legislativos, do Estado.

\section{Conclusão, a resposta à "será o século XXI um século chinês?" Caso a pergunta se refira ao} exercício de uma hegemonia no mundo, como ocorreu durante o chamado "condomínio" americano/ soviético, depois da Segunda Grande Guerra, quando as duas superpotências detinham um monopólio nuclear, então, a melhor resposta talvez seja de que a pergunta não tem mais cabimento, que o mundo da globalização significa justamente a eliminação de condições de hegemonia de apenas uma, ou mesmo duas nações. Como ocorria no passado, quando a ascensão hegemônica sucedia vitórias e conquistas na guerra e compreendia o domínio em novas tecnologias. Como a invenção da falange grega, sucedida pela legião romana. Como a dos couraçados pela Inglaterra, a de porta aviões pelos Estados Unidos. No entanto, aparentemente, guerras entre os Estados dominantes terminaram; os conflitos mundiais armados vêm se dando através de guerrilhas internas dos países periféricos.

Se a pergunta se refere à posição primeira ou segunda, por tamanho do PIB, considerando-se o ritmo do crescimento do PIB chinês, é possível que ultrapasse o americano.

No entanto, em termos de PIB per capita, considerando a dimensão da massa populacional da China, de 1,4 bilhões de habitantes, frente aos 320 milhões de americanos, torna-se crescentemente problemática a manutenção de altos ritmos de progresso, ante a elevação também crescente da questão ambiental e as limitações da utilização de recursos naturais. Sendo que o território americano aparece melhor dotado em termos de riquezas e de condições naturais.

Foi mencionada a agilidade de tomada de decisões governamentais na China, associada à implantação da ideologia comunista. No entanto, há de se considerar também a agilidade da sociedade civil ante uma necessidade imposta num dado momento. Neste sentido, considerar o número de anos entre as discriminações raciais nos transportes urbanos dos Estados Unidos e a eleição de Barack Obama indica uma alta velocidade de capacidade de mudança. A manutenção de formas autoritárias na China pode 
congelar maior agilidade popular. O que significa que não se pode descartar a possibilidade de, em acordo com Marx, o socialismo mais avançado acabe sendo implantado primeiro nos Estados Unidos.

Em diversas instâncias a globalização vem diminuindo o poder do Estado, quando a Internet ignora as fronteiras internacionais. Porém, a aventura espacial que também ignora fronteiras nacionais é comandada pelo Estado. São os Estados que promovem os mercados comuns, que através de instituições como a do G-20 controlam a economia mundial. Sair-se-ão melhor as Nações que melhor entenderem o papel do Estado na fase histórica atual.

$\mathrm{Na}$ verdade, estas são as grandes perguntas que hoje se apresentam nas encruzilhadas para o futuro. Quais os papéis a serem desempenhados pelo Estado? Onde e quando o capitalismo será realmente substituído por novo modo de produção?

\section{REFERÊNCIAS}

GUIMARÃES, Samuel Pinheiro. Desafios Brasileiros na Era dos Gigantes, 1 ed. Rio de Janeiro: Contexto, 2005. 456p.

LEFÉBVRE, Henri. La Production de L’Espace. Paris, Éditions Anthropos, 1974. 468p.

LENIN, Wladimir. Imperialismo, Etapa Superior do Capitalismo. Porto Alegre, Globo Editora, 1979. 641p.

LUPORINI, Cesare e SERENI, Emilio. El Concepto de Formación Econômica Social. Buenos Aires, Siglo XXI, 1974.

MARX, Karl e ENGELS, Frederic. A Ideologia Alemã (Feuerbach), 10 ed. São Paulo, Editora Hucitec. 1996.

MESZÁROS, István. Estrutura Social e Formas de Consciência, 2 volumes. São Paulo, Boitempo, 2011. 376p.

NORMAN, Angell. The Great Illusion, London, Wilhram Heimemann, 1910. 301p.

PEREIRA, Merval. O sonho chinês. O Globo, 10 de janeiro de 2014.

POULANTZAS, Nicos. L'Etát, le pouvoir, le socialisme. Paris, PUF, 1976. 348p.

SCHUMPATER, Joseph. Capitalismo, Socialismo e Democracia. Rio de Janeiro, Fundo de Cultura, 1961. 534p. 